\title{
LA MUERTE COMO ELEMENTO DEL DERECHO: NECRODERECHO
}

\author{
Death as element of Law: Necro rights
}

José Ramón Narváez Hernández*

Universidad Nacional Autónoma de México

\section{Resumen}

Partiendo de un interesante análisis, el autor da cuenta del fenómeno de la «muerte» y su relación con las actividades cotidianas del ser humano, promotor -inclusive- de actividad con fines lucrativos, y que el derecho no ha podido cubrir in extenso de manera adecuada.

Palabras clave: Muerte; patrimonio cultural; infrarrealismo jurídico; ética.

\section{Abstract}

Starting on an interesting analysis, the author gives an account of the phenomenon of «death» and its relation to the daily activities of the human being, promoter - also- of activity for lucrative purposes, where the law has not been able to cover in extensively appropriate way.

Keywords: Death; cultural heritage; legal infra-realism; ethics.

Doctor por la Universidad de Florencia. Investigador del Instituto de Investigaciones Jurisprudenciales y Ética Judicial en la Suprema Corte de México. Profesor en la Universidad Nacional Autónoma de México. 
La muerte es normativa, está en nuestra identidad nacional como un símbolo de castigo para los indígenas paganos en un principio lisa y llana imposición de la ley creada por el conquistador. Gradualmente se convierte en una forma de redención para los cristianos y conversos, muchos de ellos indígenas sobrevivientes de las enfermedades y excesos de los españoles, pero también la muerte se hizo mestiza, o mejor aún, transmutó en un fenómeno sincrético, también pagano más tolerado por la visión judeocristiana incrustada en la idea del Estado moderno mexicano, así plasmada en las primeras Constituciones. Morir como símbolo de redención y el Estado como espacio para esperar ese final fatal; un pueblo sufridor, como el mexicano, construyó instituciones paliativas, encargadas no de ayudar a vivir sino de facilitar el buen morir.

Los siglos XIX y XX están marcados por luchas y conflictos que significaron muerte, normalmente para la gente más humilde, hasta el terremoto de 1985 fue discriminador, pues fueron las viviendas más humildes de la Ciudad las que se vinieron abajo, los hospitales públicos y las oficinas donde estaban los empleados que entraban a trabajar muy temprano, y, por ende, no los mejor pagados - los puestos directivos en México entran después de las 10, todos lo saben-. Lo cierto es que en el imaginario fue fraguándose una idea de la muerte como fiel compañera de la sociedad mexicana.

Ahora, la muerte es patrimonio cultural, y, por tanto, sujeto de un derecho colectivo que la tutela y la fomenta, pues es fuente de ingresos de un turismo peculiar que festeja que festejemos la muerte. La muerte está en el tzompantli de nuestros sitios arqueológicos, está en nuestros murales, está en nuestra literatura, está en nuestro cine, está en nuestras instituciones. La muerte es una cosmovisión, una epistemología, una hermenéutica e incluso una poética.

En el largometraje inconcluso ;Qué viva México! (1930-1979), del cineasta soviético Serguéi Eisenstein, la muerte es el pretexto para contar iconográficamente la historia de México, comienza con el genocidio de la conquista, pasa por el exterminio de las haciendas decimonónicas y concluye con la fiesta de noviembre. La secuela por obvias razones tendría que incluir el 68, el Halconazo (1971) y la guerra sucia; Aguas Blancas (1995), Acteal (1997), Ciudad Juárez, San Fernando (2010), Ayotzinapa (2014), Tlatlaya (2014); y menos conocidas las fosas de Taxco (2010), Cinco Manantiales (2011), Durango (2011), Nuevo León (2012) y La Barca (2013); y po- 
dría seguir enunciando lugares y fechas, pero quedémonos con el dato del tercer lugar en muertes violentas debajo de Siria e Irak, 13 personas por hora. 170 mil muertos en dos sexenios — cifras conservadoras, hay quien habla de 300 mil—. La muerte hoy en día es un acontecimiento de nuestra cotidianeidad, un personaje de nuestra historia contemporánea, un compañero de viaje de nuestra historia personal. La muerte en México es santa porque se le reza para no morir.

La muerte también ha estado presente en la literatura mexicana desde siempre. Para Edmundo Valadés, en México, La muerte tiene permiso (1955), cuando un grupo de campesinos, —indígenas aseguraría yo- hartos de sufrir vejaciones y muerte, se dirige a una asamblea de autoridades agrarias para pedirles permiso de matar al presidente municipal, origen de todos sus pesares, los representantes del Estado discuten sobre la justicia, primero han despreciado y tildado de incivilizados a sus interlocutores. El cuento se convierte en una paráfrasis que poco a poco se vuelve una velada amenaza: podremos ser callados y condescendientes, pero todo tiene un límite, en un país donde la muerte opera sin permiso un día podría tenerlo, para mal y para bien. En el documental Digna hasta el último aliento (Cazals, 2004), un militar de alto rango afirma que la Constitución y la jurisprudencia de la Suprema Corte avalan la actividad del Ejército, cuya misión es la seguridad pública a todo precio, y agrega: si es necesario que eso se haga con un permiso más detallado habrá que reformar la Constitución. Algunas de las últimas reformas pudieran interpretarse de esa manera, como un permiso para matar.

En el mural denominado La epopeya de la civilización americana, de José Clemente Orozco (1934), pintado en la Baker Memorial Library (Dartmouth College. New Hampshire), el muralista mexicano ironiza con los genocidios europeos en tierras americanas, la Primera Guerra Mundial y la Conquista; entre otros temas, destaca un panel llamado "Los dioses modernos» en el cual Orozco critica abiertamente a la Universidad y a la Academia, haciéndolos de alguna manera copartícipes de esas muertes: esqueletos togados y con birrete asisten al parto de otro esqueleto más grande, que ha dado a luz a un pequeño esqueleto, este, también con birrete. No es sólo que la muerte sea un hecho en la vida de la humanidad, o concretamente de nuestra cultura, se trata de un tema transversal en el que las artes y las ciencias participan para formar un criterio de identidad que nos avasalla. 
En el infrarrealismo jurídico, movimiento al que pertenezco, lo tuvimos claro desde el principio, muerte y vida son las dos caras de una misma moneda; más allá de una simple mirada maniquea, nuestra cultura originaria llama al inframundo, mundo, otra realidad paralela con la que se convive, otro cielo, incluso, si se me permite, saber a dónde van nuestros muertos, para saber por dónde han de volver; la tragedia es que nuestros muertos están desaparecidos - literalmente- extraviados, y nosotros sin saber si han encontrado el camino al Mictlán, como Antígonas contemporáneas, sin tener los restos para poderlos enterrar, sin saber si los han devorado las aves o han sido disueltos en ácido, con la complicidad del Estado y sus paleros en la gran mayoría de casos, por eso lo hemos denominado necroderecho.

Hoy resultan irrisorias figuras como el debido proceso, los derechos humanos, el acceso a la justicia y cuanta parafernalia jurídica pudiera esgrimirse, porque en México se muere con o sin permiso.

No es un mero pesimismo nihilista, pensamos la muerte porque queremos la vida, porque la deseamos fuertemente, porque la defendemos a ultranza, y sí, somos abogados, aunque resulte extraño; y este vitalismo nuestro, que nos ha venido por un chingadazo — así le llamamos a esta toma de conciencia- nos urge a cuestionarnos el cómo nos enseñaron a operar el sistema, el cómo nos adiestraron a no hacer preguntas, el cómo nos amenazan constantemente para alinearnos, y detrás la muerte como castigo probable para el disidente, para el revolucionario, para el crítico; pero es que de otro modo no es vida; por eso la descomplicidad, para no seguir de aquel lado, tomar postura y optar por la vida; esperanzados de encontrar nuevas formas de organizarnos, de ponernos de acuerdo y resolver nuestros conflictos, quizá mirando donde otros no quisieron, más abajo, ahí donde la vida es fiesta, en nuestras comunidades indígenas, donde tiene años reconstruyendo ese camino hacia una muerte que transforma y te une con el cosmos.

Hay además una muerte sutil. Tan trágico es que mueran personas en la búsqueda de seguridad, comida y una mejor vida, como quienes todos los días mueren un poco en la infinidad de oficinas de todo el mundo, la obsesión por la producción terminó por convertirnos en objetos de una interminable cadena de explotación. Y muy pocos se dan cuenta. Los pretextos sobran para cosificar a una persona, los tiempos urgen, la demanda no se detiene, hay que aparentar que trabajamos todo ese tiempo; todo se 
convierte en una farsa macabra, la gente tiene una vida hostil dentro de cuatro paredes, puede observarse perfectamente la (no)lucha de clases, los que mueren y los que explotan, los horarios son diferentes, las prestaciones sobre todo, pero lo que más indigna es el trato, la manipulación y el chantaje; el sadismo y el saberse «amo/dueño» del otro, genera un insano gusto por el sufrimiento ajeno, la tragedia es que la cotidianeidad y la banalidad en la maldad de estas prácticas impide distinguir la magnitud del problema. Gota a gota los explotadores saben que asesinan un parte de la ya mal trecha dignidad humana, se nota en sus miradas, en la voz que somete y ningunea a muchos que pierden no sólo su salud, su familia, su espacio personal, sino hasta su vida, el cinismo llega incluso las revisiones médicas anuales in situ, no hay necesidad de dejar ni siquiera un día de asistir al trabajo, literalmente les extraen la sangre de las venas en el mismo lugar laboral.

Cada vez más personas abandonan el campo para venir a morir a las ciudades, contaminadas, atiborradas, violentas, consumistas, alienadas... esa violencia endémica que nos hace tan susceptibles, que nos indispone al diálogo y nos devuelve a ese estado de naturaleza donde el fuerte y el poderoso gobiernan. Símbolos del deterioro es la poca convivencia, la inutilidad del arte, el desprecio al ocio, pero, sobre todo, el asco a la filosofía y el pensamiento; la superficialidad nos ha apabullado a través de redes sociales cada día más indolentes, nos ha marginado a un espacio de comodidad individualista que sin darse cuenta, mira con falsa indignación la muerte en espacios lejanos, por eso es importante hablar de la muerte, como lo hace el infrarrealismo, de esos miles de cadáveres insepultos, desaparecidos o simplemente olvidados; sólo así recordaremos que estamos vivos y quizá nos rebelaremos ante esta muerte silenciosa que nos quita un poco de las chispa vital cada día con la ayuda del derecho laboral.

Otros no tienen tanta suerte. La violencia disfrazada de mil máscaras se incorpora a la vida civil con denostada insistencia. Detrás de una palabra, después de un gesto, en un acto aparentemente protector, muchas mujeres, niños, indígenas, adultos mayores, sufren el desdén de la civilización que los considera no útiles, los hace a un lado a través de programas que los marginan más, impuestos por instituciones que sólo llevan un nombre de membrete porque no corresponde con su actividad, de ahí comen un sinnúmero de burócratas ya muertos espiritualmente, zombis del sistema que sufren violencia y luego la trasladan a la sociedad, ahí también se co- 
locan los abogados, perritos falderos mansos ante la mano del Estado pero desalmados con los débiles.

Una ética que prefiriera la vida jamás pensaría en quitarle al otro la suya gota a gota, porque el victimario muere con su víctima, lo difícil es matar la primera vez, dicen los asesinos que saben de esto; la muerte en México es endémica, ya desde hace muchos años; pero esa muerte corporal, que cercena, que degüella, que mutila y disuelve; se alimenta de esta otra introyectada en los ánimos pusilánimes de mexicanos que prefirieron su tajada del pastel revolucionario, que pensaron que mientras dijeran que sí, no les pasaría nada o le pasaría al vecino. No es una crisis institucional, nunca tuvimos instituciones, son marquesinas de un espacio teatral barroco al estilo de las estaciones del tren del Guardagujas de Juan José Arreola, mucha madera, muchas luces, pero detrás nada.

Siempre fuimos burlones, quizá sea la nación que usa los sobrenombres como una costumbre ancestral, hay quien está orgulloso de su apodo, hasta pareciera que le otorgara poderes místicos, no es ese el problema, porque eso es fiesta, el problema es cuando va acompañado de lo otro, de la discriminación, de esa que hace daño, de la que busca segmentar, de la que piensa que así el poderoso verá con mejores ojos al vencedor, esa que nos divide y hace del de arriba más fuerte, por eso el fuerte desprecia la inteligencia y la creatividad, porque cuestiona su poder, prefiere que todos nos mantengamos acosando al otro, de ese modo nos volvemos también verdugos y en la complicidad y la culpa es difícil reaccionar, a todo esto simplemente le podríamos llamar opresión, y a su mecanismo favorito acoso.

El poderoso es el varón temeroso de compartir sus espacios con las mujeres, es el burócrata encumbrado que le debe el puesto a alguien, es el estúpido que no sabe reírse de sí mismo, es todo aquel que tiene en sus manos el poder de transformar al otro y en lugar de hacerlo lo destruye, sin saber que así se destruye él y que ha perdido una gran oportunidad para ser más feliz, pero usar el poder para eso requiere de un largo camino que comienza con la pregunta ¿quién soy y qué hago aquí? 